\title{
Pancultural Self-Enhancement Reloaded: A Meta-Analytic Reply to Heine (2005)
}

\author{
Constantine Sedikides \\ University of Southampton
}

\author{
Lowell Gaertner \\ University of Tennessee
}

\author{
Jack L. Vevea \\ University of California, Santa Cruz
}

\begin{abstract}
C. Sedikides, L. Gaertner, and Y. Toguchi (2003) reported findings favoring the universality of self-enhancement. S. J. Heine (2005) challenged the authors' research on evidential and logical grounds. In response, the authors carried out 2 meta-analytic investigations. The results backed the C. Sedikides et al. (2003) theory and findings. Both Westerners and Easterners self-enhanced tactically. Westerners self-enhanced on attributes relevant to the cultural ideal of individualism, whereas Easterners selfenhanced on attributes relevant to the cultural ideal of collectivism (in both cases, because of the personal importance of the ideal). Self-enhancement motivation is universal, although its manifestations are strategically sensitive to cultural context. The authors respond to other aspects of Heine's critique by discussing why researchers should empirically validate the comparison dimension (individualistic vs. collectivistic) and defending why the better-than-average effect is a valid measure of self-enhancement.
\end{abstract}

Keywords: self, culture, self-enhancement, universal self-enhancement

In an influential article, Heine, Lehman, Markus, and Kitayama (1999) drew a provocative conclusion: "The empirical literature provides scant evidence for a need for positive self-regard among Japanese and indicates that a self-critical focus is more characteristic of Japanese," "the need for self-regard must be culturally variant," and "the need for self-regard ... is not a universal, but rather is rooted in significant aspects of North American culture" (p. 766). Japanese do not have or wish to have high self-esteem (Heine, Kitayama, Lehman, et al., 2001) and, if anything, they self-criticize rather than self-enhance (Heine, Kitayama, \& Lehman, 2001). These statements reflect what we (Sedikides, Gaertner, \& Toguchi, 2003) labeled the cultural-self perspective: Selfenhancement is a uniquely Western phenomenon.

We (Sedikides et al., 2003) cast doubt on the assertion that the need for self-regard and the motivation to self-enhance were the exclusive province of North American or Western culture. After all, this assertion ran in the face of established theories highlighting the universality of self-esteem (Pyszczynski, Greenberg, Solomon, Arndt, \& Schimel, 2004a, 2004b) and of established findings regarding the psychological health benefits of selfenhancement (Taylor, Lerner, Sherman, Sage, \& McDowell, 2003a, 2003b) as well as the universality of these benefits (Ander-

Constantine Sedikides, School of Psychology, University of Southampton, England; Lowell Gaertner, Department of Psychology, University of Tennessee; Jack L. Vevea, Department of Psychology, University of California, Santa Cruz.

We thank Aiden P. Gregg for helpful comments on a draft of the article.

Correspondence concerning this article should be addressed to Constantine Sedikides, Center for Research on Self and Identity, School of Psychology, University of Southampton, Southampton SO17 1BJ, England. E-mail: cs2@soton.ac.uk son, 1999; Bonanno, Field, Kovacevic, \& Kaltman, 2002; Stewart et al., 2003). There had to be an explanation.

Conveniently, the explanation was supplied by the self-enhancing tactician model (SCENT; Sedikides \& Gregg, 2003; Sedikides \& Strube, 1997). The SCENT highlights the tactical and role-fulfilling constitution of self-enhancement. Expressions of unvarnished selfpraise are infrequent. Instead, self-enhancement is by and large tactical, acquiescing to situational, normative, and societal constraints; anticipating potentially detrimental reputational consequences; and recognizing the role-fulfilment necessity of culturally sanctioned roles (Sedikides, Campbell, Reeder, \& Elliot, 1998, 2002; Sedikides, Herbst, Hardin, \& Dardis, 2002). A rather well-worn path through which tactical self-enhancement treks is boasting on a few important, but nonboasting or even deprecating on many unimportant, selfattributes (Alicke, 1985; Sedikides, 1993; Sedikides \& Green, 2000). Important or personally valued attributes are those that imply successful role fulfilment. In more succinct terms, members of all cultures evaluate themselves positively on personally important attributes or on dimensions that imply successful enactment of culturally prescribed roles.

The agency imperative (e.g., personal effectiveness, social dominance), or the individualistic dimension, is culturally valued in the West. In contrast, the communion imperative (e.g., personal integration, social connection), or the collectivistic dimension, is culturally valued in the East. ${ }^{1}$ It follows that Westerners regard individualistic, whereas Easterners regard collectivistic, attributes

\footnotetext{
${ }^{1}$ The label "Eastern culture" (just as the label "Western culture") may mask important regional differences in self-construal. One investigation, for example, reported that Chinese are more, whereas Japanese are less, narcissistic than Americans (Fukunishi et al., 1996).
} 
as personally important (Sedikides et al., 2003, Study 2). Hence, Westerners self-enhance (i.e., positively differentiate the self from the in-group) more fervently on individualistic attributes (e.g., "I am more self-reliant than other community members"), whereas Easterners self-enhance more fervently on collectivistic attributes (e.g., "I am more loyal than other community members").

Our hypotheses were supported in two studies (Sedikides et al., 2003). Study 1 tested participants from differing cultural backgrounds (the United States vs. Japan), whereas Study 2, in a conceptual replication, tested participants of differing selfconstruals (independent vs. interdependent). Westerners (Americans in Study 1) or persons with independent self-construals (Study 2) self-enhanced on individualistic attributes, whereas Easterners (Japanese in Study 1) and persons with interdependent self-construals (Study 2) self-enhanced on collectivistic attributes. Notably, the former (independents, to be exact) regarded individualistic attributes as personally important, whereas the latter (interdependents) regarded collectivistic attributes as personally important. In turn, attribute importance mediated self-enhancement in each group. We concluded that (a) both Westerners and Easterners self-enhance, but on strategically different dimensions, (b) selfenhancement is, at least partly, due to personal importance of the comparison dimension, and, more critically, (c) self-enhancement is a universal human motivation.

Heine (2005) took issue with our findings. He argued that, although there is a modicum of empirical support for the notion that people (East Asians, in particular) self-enhance on dimensions important to them, the weight of the evidence does not favor this conjecture. Subsequently, he proceeded under the heading Why Do Sedikides et al. Fail to Replicate Past Research to provide a few explanations for this seeming empirical discrepancy.

We decided to address Heine's (2005) challenge head-on. Instead of counterarguing his objection on the basis of logic or interpretation, we opted for a more constructive approach. We put to a rigorous empirical test the premise of his challenge: the alleged Sedikides et al. (2003) nonreplication. Hence, we engaged in a meta-analytic integration of all primary studies on the topic. We describe two meta-analyses below, saving our response to Heine's explanations for the seeming empirical discrepancy and to other concerns he raised for the General Discussion.

\section{Overview}

We conducted two meta-analytic investigations in which we tested predictions derived from the SCENT model regarding cultural manifestations of self-enhancement. Both meta-analyses included data from Western and Eastern cultures. In Investigation 1, we tested the prediction that cultures vary in regard to the dimensions on which self-enhancement is expressed: Westerners self-enhance (i.e., positively differentiate self from other) more readily on individualistic attributes, whereas Easterners self-enhance more readily on collectivistic attributes. In Investigation 2, we tested the prediction that both Westerns and Easterners self-enhance to the degree to which they regard a given attribute as personally important.

\section{Investigation 1}

\section{Method}

\section{Literature Search}

We searched PsycINFO for articles published from 1872 to January 2005 using culture and self as joint search terms. The search produced eight studies from five articles, which yielded 15 samples (8 Western, 7 Eastern) that satisfied the inclusion criteria.

\section{Inclusion Criteria}

To assess whether Westerners and Easterners self-enhance on different attributes, we included studies in the meta-analysis that satisfied three criteria. First, studies had to sample either members of Western or Eastern culture. Such studies identified cultural membership on the basis of nationality (e.g., Japan, United States), ethnicity (e.g., Asian), or selfconstrual (Singelis, 1994). Second, studies had to provide a measure of one's perception of self relative to others. Participants in such studies (a) performed a distribution task in which they estimated the percentage of the population from which they are better in terms of a given attribute, (b) rated separately self and other (e.g., "To what extent does Trait A describe you [other]?": 1 = not at all, 7 = very much), with the arithmetic difference of the self-score minus other score quantifying the self-other comparison, or (c) rated simultaneously self and other on a bipolar scale anchored at the extremes by self and other (e.g., "To what extent does Trait A describe you relative to Person X?": $-5=$ much worse than Person $X$, $0=$ as well as Person $X, 5=$ much better than Person $X$ ). Finally, studies had to assess explicitly the self-other comparison on attributes associated with individualism versus collectivism. Participants in such studies compared self and other in regard to individualistic traits or behaviors (e.g., self-reliant, put myself before my group) or collectivistic traits or behaviors (e.g., loyal, do anything for my group). ${ }^{2}$

In summary, data were obtained from samples of Western or Eastern cultural members, who compared self with others on individualistic and collectivistic attributes. Table 1 displays the characteristics of the 15 samples that satisfied the inclusion criteria. Each primary study varied the dimension of self-other comparison (i.e., individualistic vs. collectivistic) as a within-subject factor and, with the exception of one study (Hornsey \& Jetten, 2005, Study 1), provided a sample of Westerners and a sample of Easterners. Each sample yielded a mean self versus other score for the individualistic and collectivistic attributes, respectively.

As detailed in the last two columns of Table 1, the samples varied in regard to two methodological issues. In 11 of the 15 samples, researchers validated empirically the individualistic and collectivistic comparison dimensions. Those studies used either factor analytic procedures or extensive pilot testing to identify attributes uniquely relevant to each dimension. In the remaining 4 samples, researchers labeled attributes as individualistic or collectivistic, but provided no empirical assurance that these attributes reflected uniquely the underlying dimensions. Consequently, we coded as a moderator whether the dimensions were empirically validated $(0=$ no, 1 = yes).

Additionally, Eastern samples varied in regard to the cultural location in which they were obtained. Three of the seven Eastern samples were obtained in an Eastern cultural locale (e.g., Japanese students living in Japan; Heine \& Lehman, 1997, Study 1), whereas four were obtained in a Western cultural locale (e.g., Japanese exchange students in the United States; Sedikides et al., 2003, Study 1). Patterns of self-enhancement may vary across Eastern samples as a function of acculturation (Heine \& Lehman, 2004). Consequently, we coded as a moderator the cultural locale $(0=$ Eastern, $1=$ Western $)$ in which Eastern samples were obtained. Such a moderator is irrelevant to the Western samples, because they were all obtained in Western locales.

\footnotetext{
2 These criteria identify a subset of studies that are relevant to our framing of the research question. There are other studies on this general topic that are not included, such as Heine and Lehman (1995), Heine, Kitayama, Lehman, et al. (2001), and Kitayama, Markus, Matsumoto, and Norasakkunkit (1997).
} 
Table 1

Characteristics of the 15 Samples Included in Investigation 1

\begin{tabular}{|c|c|c|c|c|c|}
\hline Source & Culture $^{\mathrm{a}}$ & Defined $^{\mathrm{b}}$ & Task $^{\mathrm{c}}$ & Validation $^{\mathrm{d}}$ & Locale $^{\mathrm{e}}$ \\
\hline Heine \& Lehman (1997, Study 1) & $\mathrm{E}$ & $\mathrm{N}$ : Japan & DT & $\mathrm{N}$ & E \\
\hline Heine \& Lehman (1997, Study 1) & $\mathrm{W}$ & E: European & DT & $\mathrm{N}$ & W \\
\hline Hornsey \& Jetten (2005, Study 1) & W & $\mathrm{N}$ : Australia & SE & $\mathrm{Y}$ & $\mathrm{W}$ \\
\hline Hornsey \& Jetten (2005, Study 2) & $\mathrm{E}$ & $\mathrm{N}$ : Nations in Asia & $\mathrm{SE}$ & $\mathrm{Y}$ & W \\
\hline Hornsey \& Jetten (2005, Study 2) & W & $\mathrm{N}$ : Nations in Western Europe & SE & Y & W \\
\hline Kurman (2001, Study 1) & $\mathrm{E}$ & N: Singapore & DT & Y & E \\
\hline Kurman (2001, Study 1) & $\mathrm{W}$ & N/E: Israeli-Jew & DT & $\mathrm{Y}$ & $\mathrm{W}$ \\
\hline Kurman (2001, Study 2) & E & N: Singapore & DT & $\mathrm{Y}$ & $\mathrm{E}$ \\
\hline Kurman (2001, Study 2) & $\mathrm{W}$ & N/E: Israeli-Jew & DT & $\mathrm{Y}$ & $\mathrm{W}$ \\
\hline Norasakkunkit \& Kalick (2002) & $\mathrm{E}$ & E: Asian & DT & $\mathrm{N}$ & W \\
\hline Norasakkunkit \& Kalick (2002) & W & E: European & DT & $\mathrm{N}$ & $\mathrm{W}$ \\
\hline Sedikides et al. (2003, Study 1) & $\mathrm{E}$ & $\mathrm{N}$ : Japan & SI & Y & W \\
\hline Sedikides et al. (2003, Study 1) & W & E: European-American & SI & Y & W \\
\hline Sedikides et al. (2003, Study 2) & $\mathrm{E}$ & SCS & SI & $\mathrm{Y}$ & $\mathrm{W}$ \\
\hline Sedikides et al. (2003, Study 2) & $\mathrm{W}$ & SCS & SI & $\mathrm{Y}$ & W \\
\hline
\end{tabular}

${ }^{a}$ Indicates whether participants were from Western (W) or Eastern (E) culture.

${ }^{\mathrm{b}}$ Indicates whether culture was defined by nationality (N), ethnicity (E), or self-construal scale (SCS).

${ }^{\mathrm{c}}$ Indicates whether the self-other comparison task was from a distribution task (DT) of estimating the percentage of the population one's self is better than, separate ratings (SE) of self and other on Likert-type scales, or simultaneous (SI) self-other rating on a bipolar scale.

${ }^{\mathrm{d}}$ Indicates whether $(\mathrm{Y})$ or not $(\mathrm{N})$ the study validated the comparison dimensions.

${ }^{\mathrm{e}}$ Indicates whether the culture of the location in which participants were sampled was primarily Western (W) or Eastern (E)

\section{Calculation of Effect Sizes}

The self-other data are situated conceptually in one of four conditions formed by the factorial crossing of a person's cultural membership (Western, Eastern) and the comparison dimension (individualistic, collectivistic). We transformed those data to obtain three effect sizes. One effect size addressed the issue of absolute self-enhancement, whereas two effect sizes addressed issues of relative self-enhancement.

Absolute self-enhancement. The issue of absolute self-enhancement refers to whether persons from Western and Eastern cultures, respectively, self-enhance (i.e., positively differentiate self from others). In other words, is there evidence of self-enhancement in each condition of our conceptual $2 \times 2$ design?

To address this question, we identified within each sample the criterion self-other score that reflected an equivalent self-other perception, such that scores greater than the criterion reflect self-enhancement and scores below the criterion reflect self-effacement. When the self-other score was obtained from the arithmetic difference of the self-rating minus the other rating (e.g., Hornsey \& Jetten, 2005), the criterion score is 0; a 0 score indicates an equivalent perception of self and other. When the self-other score was obtained from a bipolar scale anchored at the extremes by self and other, the criterion score is the scale midpoint, which indicates an equivalent perception of self and other. Indeed, studies using a bipolar scale (e.g., Sedikides et al., 2003) explicitly labeled the midpoint as an equivalent perception of self and other, and the value of the midpoint (i.e., criterion score) was 0 . When the self-other score was obtained from a distribution task in which participants estimated the percentage of the population from which they are better, the criterion score is the 50th percentile (i.e., 50.00 or 0.50 depending on whether studies reported percentages or proportions). ${ }^{3}$ The 50 th percentile is the standard criterion for such distribution tasks in that scores greater than 0.50 reflect a perception of self as better than average (Heine \& Lehman, 1997). ${ }^{4}$

We computed an absolute-self-enhancement effect size for each sample by subtracting the criterion score from the mean self-other rating and dividing that difference by the standard deviation of the mean self-other rating. A positive effect size reflected self-enhancement and indicates the number of standard deviations above the criterion by which participants perceived self more favorably than other. A negative effect size reflected self-effacement and indicates the number of standard deviations below the criterion by which participants perceived self less favorably than other. An effect size of zero reflected the absence of a biased self-other perception and indicates no difference between the self-other and criterion scores. Table 2 contains the effect sizes and conditional variances for the issue of absolute self-enhancement.

Relative within-culture self-enhancement. The issue of relative withinculture self-enhancement refers to whether self-other comparison is more favorable to self on the individualistic versus collectivistic comparison dimension. In regard to our conceptual $2 \times 2$ design, the issue reflects the simple effect of dimension in levels of culture.

We computed a within-culture effect size for each sample by subtracting the mean self-other rating on the individualistic dimension from the mean self-other rating on the collectivist dimension and dividing that difference by the standard deviation of the within-person difference score. ${ }^{5}$ A positive effect size indicates that the self-other comparison was more favorable to self on the individualistic than collectivistic dimension and is interpreted directly as the number of standard deviations by which the self-other comparison was more favorable to self on the individualistic than collec-

\footnotetext{
${ }^{3}$ For studies that reversed the wording of the distribution task and required participants to estimate the percentage of the population that is better than self, we reverse scored the estimate to maintain the scaling across studies. For example, we reversed an estimate of "30\% of the population is better than me" to "I am better than $70 \%$ of the population."

${ }^{4}$ Kurman (2001) used a distribution task in which participants made a dichotomous decision as to whether they are above or below average for each of three individualistic and three collectivistic traits. Kurman reported the average proportion of individualistic and collectivistic traits on which participants considered self to be above average. Assuming no preference for the above decision, the expected relative frequency for the above decision on any one trait is 0.50 . Across three traits, the expected frequency of the above decision is 1.5 out of 3.0 , which is a relative frequency of 0.50 . Consequently, the criterion score is 0.50 , in that proportions greater than 0.50 reflect a greater than chance preference for the above-average judgment.

${ }^{5}$ The standard deviation of the within-person difference score is the appropriate denominator for standardization because all studies manipulated the dimension of comparison (individualistic vs. collectivistic) as a within-subject factor. Studies, however, did not report that standard deviation, and the authors graciously provided us with the necessary information.
} 
Table 2

Absolute Self-Enhancement Effect Sizes for Each Culture and Comparison Dimension in Investigation 1

\begin{tabular}{|c|c|c|c|c|}
\hline \multirow[b]{2}{*}{ Source } & \multicolumn{2}{|c|}{ Individualistic dimension } & \multicolumn{2}{|c|}{ Collectivistic dimension } \\
\hline & $\begin{array}{l}\text { Effect } \\
\text { size }\end{array}$ & $\begin{array}{c}\text { Conditional } \\
\text { variance }\end{array}$ & $\begin{array}{l}\text { Effect } \\
\text { size }\end{array}$ & $\begin{array}{c}\text { Conditional } \\
\text { variance }\end{array}$ \\
\hline \multicolumn{5}{|c|}{ Western culture } \\
\hline Heine \& Lehman (1997, Study 1) & 1.5147 & 0.0300 & 2.2642 & 0.0502 \\
\hline Hornsey \& Jetten (2005, Study 1) & 1.3441 & 0.0492 & -0.0331 & 0.0251 \\
\hline Hornsey \& Jetten (2005, Study 2) & 0.6219 & 0.0889 & 0.2214 & 0.0846 \\
\hline Kurman (2001, Study 1) & 2.1111 & 0.0258 & 1.4800 & 0.0167 \\
\hline Kurman (2001, Study 2) & 1.4400 & 0.0146 & 1.0345 & 0.0110 \\
\hline Norasakkunkit \& Kalick (2002) & 0.5238 & 0.0088 & 1.9504 & 0.0225 \\
\hline Sedikides et al. (2003, Study 1) & 1.2420 & 0.0482 & 0.0558 & 0.0264 \\
\hline Sedikides et al. (2003, Study 2) & 1.5432 & 0.0490 & -0.5457 & 0.0252 \\
\hline \multicolumn{5}{|c|}{ Eastern culture } \\
\hline Heine \& Lehman (1997, Study 1) & 0.0523 & 0.0127 & 0.3467 & 0.0136 \\
\hline Hornsey \& Jetten (2005, Study 1) & - & - & - & - \\
\hline Hornsey \& Jetten (2005, Study 2) & -0.0530 & 0.0846 & 0.9724 & 0.1476 \\
\hline Kurman (2001, Study 1) & 1.0357 & 0.0110 & 1.3846 & 0.0140 \\
\hline Kurman (2001, Study 2) & 0.3714 & 0.0084 & 1.2069 & 0.0137 \\
\hline Norasakkunkit \& Kalick (2002) & 0.3594 & 0.0074 & 0.7668 & 0.0091 \\
\hline Sedikides et al. (2003, Study 1) & 0.6117 & 0.0316 & 1.5987 & 0.0625 \\
\hline Sedikides et al. (2003, Study 2) & -0.6142 & 0.0261 & 2.0968 & 0.0725 \\
\hline
\end{tabular}

tivistic dimension. A negative effect size indicates that the self-other comparison was more favorable to self on the collectivistic than individualistic dimension and is interpreted directly as the number of standard deviations by which the self-other comparison was more favorable to self on the collectivistic than individualistic dimension. An effect size of zero indicates that the self-other comparison was equivalent on the two dimensions. Table 3 contains the effect sizes and conditional variances for the issue of within-culture self-enhancement.

A point of clarification might be helpful to distinguish the relative within-culture effect size from the absolute self-enhancement effect size. Neither a positive nor a negative within-culture effect size indicates whether persons perceived self more or less favorably than other. Such an issue is directly assessed by the absolute self-enhancement effect. The within-culture effect addresses whether the self-other comparison was relatively more favorable for self on the individualistic than collectivistic dimension. For example, a person might perceive self less favorably than other by 5 units on the individualistic dimension and 7 units on the collectivistic dimension. Such patterns would produce a negative absolute self-enhancement effect on the individualistic than collectivistic dimension, respectively, and a positive within-culture effect. The latter positive effect reflects the less pronounced other-favoring bias on the individualistic dimension (i.e., -5 vs. -7 ). That is, self-other comparison was relatively more favorable to self on the individualistic than collectivistic dimension.

Relative between-cultures self-enhancement. The issue of relative between-cultures self-enhancement refers to whether social comparison is more favorable to self among members of Western versus Eastern culture. We assessed this issue separately for the individualistic and collectivistic dimensions to test the possibility that the direction or magnitude of a cultural difference varies with comparison dimension. In regard to our conceptual $2 \times 2$ design, the issue reflects the simple effect of culture in levels of dimension.

We computed a between-cultures effect size for each study by subtracting the mean self-other rating of the Eastern sample from the mean self-other rating of the Western sample and dividing that difference by the standard deviation of the self-other rating pooled across samples. A positive effect size indicates that the self-other comparison was more

Table 3

Within-Culture Self-Enhancement Effect Sizes for Each Culture in Investigation 1

\begin{tabular}{lccccc}
\hline & \multicolumn{2}{c}{ Western culture } & & \multicolumn{2}{c}{ Eastern culture } \\
\cline { 2 - 3 } \multicolumn{1}{c}{ Source } & $\begin{array}{c}\text { Effect } \\
\text { size }\end{array}$ & $\begin{array}{c}\text { Conditional } \\
\text { variance }\end{array}$ & & $\begin{array}{c}\text { Effect } \\
\text { size }\end{array}$ & $\begin{array}{c}\text { Conditional } \\
\text { variance }\end{array}$ \\
\hline Heine \& Lehman (1997, Study 1) & -0.4772 & 0.0153 & & -0.2449 & 0.0132 \\
Hornsey \& Jetten (2005, Study 1) & 0.9550 & 0.0372 & & - & - \\
Hornsey \& Jetten (2005, Study 2) & 0.3602 & 0.0778 & & -0.6825 & 0.1195 \\
Kurman (2001, Study 1) & 0.0312 & 0.0079 & & -0.1842 & 0.0072 \\
Kurman (2001, Study 2) & 0.1714 & 0.0072 & & -0.5946 & 0.0107 \\
Norasakkunkit \& Kalick (2002) & -0.8633 & 0.0106 & & -0.3823 & 0.0075 \\
Sedikides et al. (2003, Study 1) & 0.7024 & 0.0333 & & -0.6176 & 0.0317 \\
Sedikides et al. (2003, Study 2) & 1.3317 & 0.0422 & & -1.7605 & 0.0575 \\
\hline
\end{tabular}


favorable to self for Westerners than Easterners and is interpreted as the number of standard deviations by which the social comparison was more favorable to self for Westerners than Easterners. A negative effect size indicates that the self-other comparison was more favorable to self for Easterners than Westerners and is interpreted as the number of standard deviations by which social comparison was more favorable to self for Easterners than Westerners. An effect size of zero indicates that the self-other comparison was equivalent between Westerners and Easterners.

As with the within-culture effect size, the valence of the betweencultures effect does not indicate whether persons perceived self more or less favorably than other (i.e., absolute self-enhancement). The betweencultures effect indicates whether social comparison was relatively more favorable to self among Westerners or Easterners. Table 4 contains the effect sizes and conditional variances for the issue of between-cultures self-enhancement.

\section{Results}

We opted a priori for the random-effects model (called "mixedeffects model" when moderator variables are included to account for systematic between-studies variation) as opposed to the fixedeffects model, for two reasons. First, the generalization basis of the random- or mixed-effects model is broader; that is, conclusions from this model generalize to contexts of all possible operational definitions, whereas conclusions from the fixed-effects model generalize only to contexts involving the operational definition used by the meta-analyzed studies. The second reason has to do with the tendency for data to violate the homogeneity assumption of the fixed-effects model. (For extended discussions, see Field, 2001, 2003; Hedges \& Vevea, 1998; Hunter \& Schmidt, 2000; National Research Council, 1992.) However, we also carried out a parallel series of fixed-effects models to ensure that our analytic strategy did not lead us to radically different conclusions. We estimated the parameters for the random- or mixed-effects models with unconditional maximum likelihood using a computer program developed for that purpose (Vevea \& Hedges, 1995; Vevea \& Woods, 2004). We estimated fixed-effects models by weighted least squares, which is also a maximum likelihood procedure in this context. We conducted tests of the model parameters using large-sample $Z$ tests, which we calculated by dividing parameter estimates by their respective standard errors.

In all instances, the two classes of models yielded similar parameter estimates. However, each $Q$ test of the fixed-effect model's homogeneity assumption revealed excessive variability among effect sizes, which indicates that the random- or mixedeffects model is more appropriate and cautions against interpretation of inferential tests (i.e., $p$ values) from fixed-effects models because of inflated Type I error rates. Consequently, we discuss the results in regard to the random- or mixed-effects model.

\section{Absolute Self-Enhancement}

We examined separately absolute self-enhancement for members of Western and Eastern culture on the individualistic and collectivistic comparison dimensions. In each instance, we tested the moderating effect of whether studies validated empirically the dimension and, for Easterners, the cultural location in which samples were obtained.

Western culture. Westerners self-enhanced on the individualistic dimension, such that they evaluated self more favorably than other by 1.3 standard deviations above the criterion score $(g=$ $1.301, Z=7.471, p=.0001)$. This effect was not moderated by dimension validation $(Z=1.226, p=.2202$ ). (See top panel of Table 5.)

In contrast, self-enhancement on the collectivistic dimension was moderated by dimension validation $(Z=-3.412, p=.0006)$. No self-enhancement was observed in studies that involved dimension validation $(g=0.381, Z=1.520, p=.1285)$, although this effect was significant in studies that did not validate the dimension ( $g=2.102, Z=4.804, p=.0001)$. (See bottom panel of Table 5.)

Eastern culture. Easterners did not self-enhance on the individualistic dimension ( $g=0.268, Z=1.449, p=.1473)$. Neither cultural location in which the Eastern samples were obtained $(Z=$ $-1.179, p=.2384)$ nor dimension validation $(Z=0.216, p=$ .8214) moderated this pattern. (See top panel of Table 6.)

Self-enhancement on the collectivistic dimension was not moderated by cultural location $(Z=0.946, p=.3444)$. Selfenhancement, however, was moderated by dimension validation ( $Z=4.340, p=.0001)$. Easterners self-enhanced among studies that validated the dimension $(g=1.430, Z=11.334, p=.0001)$, whereas this pattern was weaker, but still significant, among studies that did not validate the dimension $(g=0.567, Z=2.661$, $p=$.0078). (See bottom panel of Table 6.)

In summary, the absolute self-enhancement effect sizes provide evidence that self-enhancement is not a uniquely Western motivation. Easterners positively differentiated self from others on at-

Table 4

Between-Cultures Self-Enhancement Effect Sizes for Each Comparison Dimension in Investigation 1

\begin{tabular}{|c|c|c|c|c|}
\hline \multirow[b]{2}{*}{ Source } & \multicolumn{2}{|c|}{ Individualistic dimension } & \multicolumn{2}{|c|}{ Collectivistic dimension } \\
\hline & $\begin{array}{c}\text { Effect } \\
\text { size }\end{array}$ & $\begin{array}{c}\text { Conditional } \\
\text { variance }\end{array}$ & $\begin{array}{c}\text { Effect } \\
\text { size }\end{array}$ & $\begin{array}{c}\text { Conditional } \\
\text { variance }\end{array}$ \\
\hline Heine \& Lehman (1997, Study 1) & 1.3378 & 0.0315 & 1.7306 & 0.0356 \\
\hline Hornsey \& Jetten (2005, Study 1) & - & - & - & - \\
\hline Hornsey \& Jetten (2005, Study 2) & 0.7655 & 0.1444 & -0.773 & 0.1505 \\
\hline Kurman (2001, Study 1) & 0.3783 & 0.0150 & 0.0392 & 0.0147 \\
\hline Kurman (2001, Study 2) & 0.7626 & 0.0158 & -0.1724 & 0.0148 \\
\hline Norasakkunkit \& Kalick (2002) & 0.1556 & 0.0144 & 0.7521 & 0.0154 \\
\hline Sedikides et al. (2003, Study 1) & 0.9728 & 0.0561 & -1.1246 & 0.0581 \\
\hline Sedikides et al. (2003, Study 2) & 2.1045 & 0.0652 & -2.5774 & 0.0770 \\
\hline
\end{tabular}


Table 5

Mixed-Effects Analysis of Absolute Self-Enhancement for Western Culture by Comparison Dimension in Investigation 1

\begin{tabular}{lllll}
\hline Model and parameter & Estimate & $S E$ & $Z$ & $p>|Z|$ \\
\hline
\end{tabular}

Individualistic dimension $^{\mathrm{a}}$

\begin{tabular}{lllll} 
Dimension validation $^{\mathrm{b}}$ & & & & \\
$\quad$ Intercept & 0.989 & 0.299 & 3.315 & .0009 \\
$\quad$ Validation & 0.430 & 0.351 & 1.226 & .2202 \\
$\quad$ VC & 0.160 & 0.099 & & \\
$\quad \begin{array}{l}\text { Simple (intercept only or } \\
\quad \text { average effect size) }\end{array}$ & & & & \\
$\quad$ Intercept & 1.301 & 0.174 & 7.471 & .0000 \\
$\quad$ VC & 0.205 & 0.117 & & \\
\hline
\end{tabular}

Collectivistic dimension ${ }^{\mathrm{a}}$

\begin{tabular}{lrrrr} 
Validation $^{\mathrm{b}}$ & & & & \\
Intercept & 2.102 & 0.437 & 4.804 & .0000 \\
Validation & -1.720 & 0.504 & -3.412 & .0006 \\
VC & 0.349 & 0.181 & & \\
\hline
\end{tabular}

Note. Variance component ( $\mathrm{VC}$ ) is estimated as a parameter in the mixed-effects analysis, and its inferential test is equivalent to the homogeneity test in the fixed-effects analysis.

${ }^{\mathrm{a}} \mathrm{k}=8 . \quad{ }^{\mathrm{b}}$ Dimension validation $(0=$ no, $1=$ yes $)$

tributes relevant to the collectivistic dimension. Additionally, the analysis detected significant variation between studies that did versus did not validate the collectivistic dimension. Studies that validated this dimension detected stronger self-enhancement among Easterners and weaker self-enhancement among Westerners compared with studies that did not validate the dimension. Finally, patterns of self-enhancement did not vary among Eastern samples as a function of the cultural locale in which those samples were obtained. The remaining analyses test directly predictions of the SCENT model by examining relative patterns of self-other comparison.

\section{Within-Culture Self-Enhancement}

The within-culture effect assesses whether the self-other comparison was more favorable to self on the individualistic versus collectivistic dimension. Each sample yielded one within-culture effect size (i.e., data are statistically independent across samples), which enabled us to include all 15 effects in a single analysis and test a relatively complex model. In particular, we tested whether the within-culture effect varied by culture $(0=$ Eastern, $1=$ Western), validation of the comparison dimension $(0=$ no, $1=$ yes), and the interaction between culture and validation. As displayed in Table 7 , the within-culture effect varied significantly as a function of the Culture $\times$ Validation interaction $(Z=3.535, p=$ .0004).

We decomposed the interaction by estimating the mean withinculture effect for each culture within levels of dimension validation. Studies that validated the comparison dimensions revealed patterns consistent with the SCENT model: The self-other comparison was more favorable for Westerners on the individualistic than collectivistic dimension ( $g=0.564, Z=3.335, p=.0009$ ) and more favorable for Easterners on the collectivistic than individualistic dimension $(g=-0.722, Z=-3.825, p=.0001)$.
Table 6

Mixed-Effects Analysis of Absolute Self-Enhancement for Eastern Culture by Comparison Dimension in Investigation 1

\begin{tabular}{|c|c|c|c|c|}
\hline Model and parameter & Estimate & $S E$ & $Z$ & $p>|Z|$ \\
\hline \multicolumn{5}{|c|}{ Individualistic dimension $^{\mathrm{a}}$} \\
\hline \multicolumn{5}{|l|}{ Dimension locale ${ }^{b}$} \\
\hline Intercept & 0.487 & 0.250 & 1.950 & .0511 \\
\hline Locale & -0.400 & 0.339 & -1.179 & .2384 \\
\hline $\mathrm{VC}$ & 0.177 & 0.106 & & \\
\hline \multicolumn{5}{|l|}{ Cultural validation $^{\mathrm{c}}$} \\
\hline Intercept & 0.208 & 0.333 & 0.623 & .5334 \\
\hline Validation & 0.086 & 0.400 & 0.216 & .8294 \\
\hline $\mathrm{VC}$ & 0.212 & 0.126 & & \\
\hline \multicolumn{5}{|l|}{$\begin{array}{c}\text { Simple (intercept only or } \\
\text { average effect size) }\end{array}$} \\
\hline Intercept & 0.268 & 0.185 & 1.449 & .1475 \\
\hline $\mathrm{VC}$ & 0.215 & 0.127 & & \\
\hline \multicolumn{5}{|c|}{ Collectivistic dimension ${ }^{\mathrm{a}}$} \\
\hline \multicolumn{5}{|l|}{ Cultural locale } \\
\hline Intercept & 0.979 & 0.275 & 3.564 & .0004 \\
\hline Locale & 0.360 & 0.381 & 0.946 & .3444 \\
\hline $\mathrm{VC}$ & 0.213 & 0.132 & & \\
\hline \multicolumn{5}{|l|}{ Validation } \\
\hline Intercept & 0.567 & 0.154 & 2.661 & .0078 \\
\hline Validation & 0.863 & 0.199 & 4.340 & .0000 \\
\hline $\mathrm{VC}$ & 0.036 & 0.038 & & \\
\hline
\end{tabular}

Note. Variance component ( $\mathrm{VC})$ is estimated as a parameter in the mixed-effects analysis and its inferential test is equivalent to the homogeneity test in the fixed-effects analysis.

${ }^{\mathrm{a}} \mathrm{k}=7 .{ }^{\mathrm{b}}$ Cultural locale $(0=$ Eastern, $1=$ Western $) . \quad{ }^{\mathrm{c}}$ Dimension validation $(0=$ no, $1=$ yes $)$.

However, studies that did not validate the dimensions suggested that the self-other comparison was more favorable for Westerners on the collectivistic than individualistic dimension $(g=-0.673$, $Z=-2.429, p=.0151)$ and that self-other comparison for Easterners did not vary across dimensions $(g=-0.315, Z=$ $-1.146, p=.2517)$.

\section{Between-Cultures Self-Enhancement}

The between-cultures effect assesses whether the self-other comparison was more favorable to self for Westerners versus

Table 7

Mixed-Effects Analysis of Within-Culture Self-Enhancement as a Function of Culture and Comparison Dimension Validation $(K=15)$ in Investigation 1

\begin{tabular}{lrcrc}
\hline \multicolumn{1}{c}{ Parameter } & Estimate & $S E$ & $Z$ & $p>|Z|$ \\
\hline Intercept & -0.315 & 0.276 & -1.146 & .2517 \\
Culture & -0.358 & 0.390 & -0.918 & .3585 \\
Validation & -0.407 & 0.333 & -1.222 & .2218 \\
Culture $\times$ Validation & 1.645 & 0.465 & 3.535 & .0004 \\
VC & 0.141 & 0.063 & & \\
\hline
\end{tabular}

Note. The model involves main and interactive effect of culture $(0=$ Eastern, $1=$ Western $)$ and validation $(0=$ no, $1=$ yes $)$. Effect size is scored as individualistic dimension-collectivistic dimension. Variance component (VC) is estimated as a parameter in the mixed-effects analysis, and its inferential test is equivalent to the homogeneity test in the fixedeffects analysis. 
Easterners. We analyzed separately the between-cultures effect for the individualistic and collectivistic dimensions to avoid complications involving lack of statistical independence (i.e., participants provided self-other data on both dimension as a within-subject measure).

Consistent with the SCENT model, self-other comparison on the individualistic dimension was more favorable to self for Westerners than Easterners $(g=0.904, Z=3.982, p=.0001)$. That pattern was not moderated by dimension validation $(Z=0.510$, $p=.6101$ ). (See top panel of Table 8.)

The between-cultures difference on the collectivistic dimension, however, was moderated by validation $(Z=-3.123, p=.0018)$. Studies that validated the dimension revealed a pattern consistent with the SCENT model: Self-other comparison on collectivistic attributes was more favorable to self for Easterners than Westerners $(g=-0.893, Z=-2.410, p=.0160)$. On the other hand, studies that did not validate the dimension revealed the opposite pattern, indicating that self-other comparison on collectivistic attributes was more favorable to self for Westerners than Easterners $(g=1.234, Z=2.161, p=.0307)$.

\section{Discussion}

According to the SCENT model, self-enhancement is a universal motivation that is carried out tactically. Rather than enhancing indiscriminately and unswervingly, people pursue and protect a positive view of self on valued domains. Given that value is defined, in part, by cultural standards, the SCENT model predicts that members of different cultures will vary in regard to the specific domain on which self-enhancement is expressed. Westerners will be most apt to self-enhance on the culturally valued dimension of individualism, Easterners on the culturally valued dimension of collectivism.

Table 8

Mixed-Effects Analysis of Between-Cultures Self-Enhancement by Comparison Dimension Validation in Investigation 1

\begin{tabular}{|c|c|c|c|c|}
\hline Model and parameter & Estimate & $S E$ & $Z$ & $p>|Z|$ \\
\hline \multicolumn{5}{|c|}{ Individualistic dimension $^{a}$} \\
\hline \multicolumn{5}{|l|}{ Dimension validation $^{\mathrm{b}}$} \\
\hline Intercept & 0.731 & 0.404 & 1.809 & .0705 \\
\hline Validation & 0.247 & 0.484 & 0.510 & 6101 \\
\hline $\mathrm{VC}$ & 0.303 & 0.185 & & \\
\hline \multicolumn{5}{|l|}{$\begin{array}{c}\text { Simple (intercept only or } \\
\text { average effect size) }\end{array}$} \\
\hline Intercept & 0.904 & 0.227 & 3.982 & .0001 \\
\hline $\mathrm{VC}$ & 0.316 & 0.192 & & \\
\hline
\end{tabular}

Collectivistic dimension ${ }^{\mathrm{a}}$

\begin{tabular}{lrrrr} 
Validation $^{\mathrm{b}}$ & & & & \\
Intercept & 1.234 & 0.571 & 2.161 & .0307 \\
Validation & -2.127 & 0.681 & -3.123 & .0018 \\
VC & 0.628 & 0.363 & & \\
\hline
\end{tabular}

Note. Variance component (VC) is estimated as a parameter in the mixed-effects analysis, and its inferential test is equivalent to the homogeneity test in the fixed-effects analysis.

${ }^{\mathrm{a}} \mathrm{k}=7$. ${ }^{\mathrm{b}}$ Dimension validation $(0=$ no, $1=$ yes $)$.
We meta-analyzed data from seven Eastern and eight Western culture samples in which participants compared self and others on attributes relevant to individualism and collectivism. From those samples, we computed effect sizes that addressed the issue of absolute self-enhancement (i.e., do persons positively differentiate self from other?), within-culture self-enhancement (i.e., are selfother comparisons more favorable to self on the individualistic or collectivistic dimension?), and between-cultures self-enhancement (i.e., are self-other comparisons more favorable to self for Westerners or Easterners?). We distinguished among samples in regard to whether Eastern samples were obtained in a locale dominated by Western versus Eastern culture and whether the primary study validated empirically the individualistic and collectivistic comparison dimensions. The latter, but not the former, distinction moderated self-other comparison.

Data from the 11 (5 Eastern, 6 Western) samples that validated the attributes comprising the individualistic and collectivistic dimensions are consistent with the SCENT model. Analysis of absolute self-enhancement indicates that Westerners evaluated self more favorably than other on individualistic but not collectivistic attributes. Easterners, on the other hand, evaluated self more favorably than other on collectivistic but not individualistic attributes. Analysis of the within-culture effect indicates that the tendency to evaluate self more positively than other was significantly stronger for Westerners on individualistic than collectivistic attributes and was significantly stronger for Easterners on collectivistic than individualistic attributes. Analysis of the betweencultures effect indicates that Westerners positively evaluate self than other more strongly than do Easterners on individualistic attributes, whereas Easterners positively evaluate self than other more strongly than do Westerners on collectivistic attributes. These results are inconsistent with the proposition of the culturalself perspective that self-enhancement is limited to Western culture. Not only do Easterners self-enhance, but they do so more emphatically than Westerners on attributes relevant to the normative imperative of Eastern culture (i.e., collectivism).

Data from the four (two Eastern, two Western) samples that did not validate the comparison dimensions (particularly the collectivistic one) are ambiguous in that they are inconsistent both with the SCENT model and the cultural-self perspective. Westerners and Easterners evaluated self more favorably than other on collectivistic attributes (a pattern inconsistent with the cultural-self perspective), and this tendency was stronger for Westerners than Easterners (a pattern inconsistent with the SCENT model). We suggest that the ambiguity of these results is due to the fact that the collectivistic attributes were not empirically validated. We return to this issue in the General Discussion.

\section{Investigation 2}

The SCENT model suggests that Westerners and Easterners self-enhance on different attributes (i.e., individualistic vs. collectivistic) because their respective cultures emphasize different norms that imbue attributes with importance. The same fundamental process, however, operates across cultures: People maintain positive self-regard by self-enhancing tactically on attributes that are personally important.

To test this proposition, we meta-analyzed data from studies in which Westerners or Easterners compared self and others on 
Table 9

Characteristics and Effect Sizes for the 12 Samples Included in Investigation 2

\begin{tabular}{|c|c|c|c|c|c|c|}
\hline Source & Culture $^{\mathrm{a}}$ & Defined $^{b}$ & Task $^{\mathrm{c}}$ & Locale $^{\mathrm{d}}$ & $r$ & $\begin{array}{c}\text { Conditional } \\
\text { variance }^{\mathrm{e}}\end{array}$ \\
\hline Brown \& Kobayashi (2002, Study 1) & $\mathrm{E}$ & $\mathrm{N}$ : Japan & SE & $\mathrm{E}$ & .2706 & 0.0556 \\
\hline Brown \& Kobayashi (2002, Study 1) & $\mathrm{W}$ & E: European & SE & W & .2959 & 0.0313 \\
\hline Brown \& Kobayashi (2002, Study 2) & $\mathrm{E}$ & N: Japan & SE & $\mathrm{E}$ & .1075 & 0.0294 \\
\hline Brown \& Kobayashi (2002, Study 3) & $\mathrm{E}$ & $\mathrm{N}$ : Japan & SE & $\mathrm{E}$ & .1357 & 0.0556 \\
\hline Heine \& Lehman (1997, Study 1) & $\mathrm{E}$ & $\mathrm{N}$ : Japan & DT & $\mathrm{E}$ & .4106 & 0.0130 \\
\hline Heine \& Lehman (1997, Study 1) & $\mathrm{W}$ & E: European & DT & $\mathrm{W}$ & .3860 & 0.0139 \\
\hline Heine \& Lehman (1999) & $\mathrm{E}$ & N: Japan & SE & $\mathrm{E}$ & .0393 & 0.0066 \\
\hline Heine \& Lehman (1999) & $\mathrm{W}$ & E: European & SE & W & .0566 & 0.0123 \\
\hline Kobayashi \& Brown (2003) & $\mathrm{E}$ & $\mathrm{N}$ : Japan & SE & $\mathrm{E}$ & .2362 & 0.0196 \\
\hline Kobayashi \& Brown (2003) & $\mathrm{W}$ & N: United States & SE & $\mathrm{W}$ & .2024 & 0.0182 \\
\hline Sedikides et al. (2003, Study 2) & $\mathrm{E}$ & SCS & SI & W & .3574 & 0.0222 \\
\hline Sedikides et al. (2003, Study 2) & $\mathrm{W}$ & SCS & SI & $\mathrm{W}$ & .3516 & 0.0222 \\
\hline
\end{tabular}

${ }^{a}$ Indicates whether participants were from Western (W) or Eastern (E) culture.

${ }^{b}$ Indicates whether culture was defined by nationality $(\mathrm{N})$, ethnicity $(\mathrm{E})$, or self-construal scale (SCS).

' Indicates whether the self-other comparison task was from a distribution task (DT) of estimating the percentage of the population one's self is better than, separate ratings (SE) of self and other on single-item scales, or simultaneous (SI) self-other rating on a bipolar scale.

${ }^{\mathrm{d}}$ Indicates whether the culture of the location in which participants were sampled was primarily Western (W) or Eastern (E).

e Conditional variances are given for the correlations after transformation by Fisher's Z, the metric in which they were analyzed.

multiple attributes and rated the subjective importance of those attributes. The multiple ratings are particularly informative because they enable the calculation of a within-person correlation. Such a correlation provides an idiographic assessment of the extent to which self-enhancement (i.e., self-other rating) covaries with the subjective value of the comparison dimension (i.e., attribute).

The SCENT model predicts that social comparison becomes more favorable to self to the degree that the comparison dimension is important. It follows that self-enhancement should correlate positively with attribute importance regardless of culture. In contrast, the cultural-self perspective predicts that culture moderates the association between self-enhancement and attribute importance. It follows that Westerners should evidence a positive correlation and Easterners should evidence no association between self-enhancement and importance. Such a prediction stems from the perspective's proposition that self-enhancement is a uniquely Western motivation.

\section{Method}

\section{Literature Search}

We searched PsycINFO for articles published from 1872 to January 2005 using culture and self as joint search terms. We also included data that were not reported in a published article (Heine \& Lehman, 1997, Experiment 1). The search identified seven studies from five articles, which yielded 12 samples ( 5 Western, 7 Eastern) that fit the inclusion criteria.

\section{Inclusion Criteria}

We included studies if they satisfied three criteria. The first two are those of Study 1, such that studies had to (a) sample either members of Western or Eastern culture and (b) measure perception of self versus other. Additionally, studies had to ideographically assess the subjective value of the attributes on which participants compared self and other. Participants in such studies rated the importance or value of each attribute on which they compared self and other. ${ }^{6}$

Table 9 displays the characteristics of the 12 samples that satisfied the inclusion criteria. ${ }^{7}$ As the Locale column of the table indicates, one Eastern sample was obtained in a Western locale (i.e., Sedikides et al., 2003). That sample consisted of persons who, according to the self-construal scale (Singelis, 1994), have a relatively high interdependent self-construal and a relatively low independent self-construal. Unsurprisingly, excluding that sample from the meta-analysis altered neither conclusions based on probablity values nor the estimated magnitude of the effect size. Consequently, we retained that sample in the analysis.

\section{Calculation of Effect Sizes}

Each participant in the included samples provided a self-other rating and corresponding importance rating on multiple attributes, with the number of attributes ranging across studies from 8 to 32 . Authors of the primary studies graciously provided the average within-person correlation between the self-other rating and the importance rating (across the multiple attributes) for the Western and Eastern sample, respectively. A positive correlation indicates that the self-other comparison became increasingly favorable to self as the importance of the comparison dimension (i.e., attribute) increased. A negative correlation indicates that the self-other comparison became increasingly favorable to self as the importance of the comparison dimension decreased. A correlation of zero indicates that the self-other comparison shared no linear association with the importance of the comparison dimension. The last two columns of Table 9 display the average within-person correlation and the corresponding conditional variance for each sample. We transformed those correlations with Fisher's $Z$ prior to analysis.

\footnotetext{
${ }^{6}$ Heine and Renshaw (2002) obtained importance ratings from a sample of participants different than those who made the self-other comparisons. We necessarily excluded those data because the importance ratings do not reflect the subjective value of the comparison dimension.

${ }^{7}$ Ito (1999) reported data from an Eastern sample that satisfied our inclusion criteria. The article, however, does not contain sufficient information to calculate the desired effect size, and Ito was unable to provide us with the relevant information. Our concern with this exclusion is mitigated by the fact that Ito's result patterns are consistent with our meta-analytic findings. Thus, his results would reinforce, rather than weaken, our conclusions.
} 


\section{Results and Discussion}

As in Investigation 1, we opted a priori for the random- or mixed-effects model and concurrently tested a parallel series of fixed-effects models. In this instance, the homogeneity assumption of the fixed-effects analysis was satisfied, as indicated by the $Q$ statistic. In any event, the two classes of statistical analysis yielded very similar estimates and conclusions based on inferential tests. For economy and consistency of exposition, we present only the results of the random- or mixed-effects model in Table 10.

The correlation between self-other comparison and the importance of the comparison dimension was significant and positive ( $r$ transformed back from Fisher's $Z]=.23, \mathrm{Z}=4.760, p=$ .0001). Importantly, this effect was not moderated by culture $(Z=$ $0.340, p=.7339)$. These results are consistent with the SCENT model. Westerners and Easterners manifested social comparisons that increasingly favored the self to the extent the comparison dimension was subjectively valued. The findings disconfirm the cultural-self perspective, which anticipated a positive association between self-enhancement and importance for Westerners, but no association for Easterners.

\section{General Discussion}

People strategically sustain positive self-regard by accentuating their distinctiveness on personally important domains. Such tactical self-enhancement, however, is not culture blind. Instead, it operates synergistically with cultural norms to sustain and promote self-regard. Those norms imbue attributes and actions with meaning and worth and consequently shape the dimensions on which self-enhancement is expressed. Eastern norms emphasize connectedness and social harmony, and Easterners perceive themselves positively in terms of actions and attributes that facilitate the cultural ideal of collectivism. Western norms emphasize independence and uniqueness, and Westerners perceive themselves positively in terms of actions and attributes that facilitate the cultural ideal of individualism. Those culture-specific manifestations of self-enhancement motivation are influenced by the same fundamental process. Indeed, the results of two meta-analytic investi-

Table 10

Mixed-Effects Analysis of Within-Person Correlation Between Self-Enhancement and Importance as a Function of Culture in Investigation 2

\begin{tabular}{lcccc}
\hline \multicolumn{1}{c}{ Model and parameter } & Estimate & $S E$ & $Z$ & $p>|Z|$ \\
\hline Dimension culture & & & & \\
$\quad$ Intercept & & & & \\
$\quad$ Culture & 0.222 & 0.065 & 3.415 & .0006 \\
$\quad$ VC & 0.034 & 0.100 & 0.340 & .7339 \\
$\quad$ Simple (intercept only or & 0.009 & 0.010 & & \\
$\quad$ average effect size) & & & & \\
$\quad$ Intercept & 0.238 & 0.050 & 4.760 & .0000 \\
$\quad$ VC & 0.009 & 0.010 & & \\
\hline
\end{tabular}

Note. Analyses and results are with the Fisher's $Z$ conversion of the Pearson correlation. Variance component (VC) is estimated as a parameter in the mixed-effects analysis, and its inferential test is equivalent to the homogeneity test in the fixed-effects analysis.

${ }^{\text {a }}$ Culture $(0=$ Eastern, $1=$ Western $)$. gations showed that people tactically self-enhance on personally valued dimensions. Self-enhancement is a universal motivation.

We hope that our meta-analytic results address satisfactorily Heine's (2005) challenge of the Sedikides et al. (2003) findings and his concern about their replicability. We now turn to other concerns that Heine raised in his critique.

\section{Should the Comparison Dimension Be Empirically Validated?}

Heine (2005) questioned whether the comparison dimension needs to be empirically validated independently of the researchers' preconceptions. In his own words, "I am inclined to trust the researchers' interpretations of independent and interdependent selves at least as much as those of the students learning about them" (p. 534). He should not be so inclined. The literature on confirmation bias aside, researchers should not be in the business of offering their idiosyncratic opinions as validation of a construct. We submit that the researcher is like a judge who must accept the empirical jury (i.e., the participants). This point acquires particular relevance in the context of the findings of Investigation 1: Selfother comparisons were moderated by whether the primary study validated empirically the comparison dimensions.

Let us elaborate. Four samples (two Eastern, two Western) did not validate the comparison dimensions. The results were inconsistent both with the SCENT model and the cultural-self perspective. How can this ambiguity be explained? It is worth noting that the two studies from which these samples were obtained (Heine \& Lehman, 1997; Norasakkunkit \& Kalick, 2002) used the same set of attributes to represent the collectivistic dimension: cooperative, loyal, considerate, hardworking, and dependable. The first three attributes appear to be face-valid indicators of collectivism. The latter two traits (hardworking and dependable), however, do not necessarily distinguish between collectivism and individualism. Even a rugged individualist might take pride in being hardworking and dependable. Those studies cite either an article (Markus \& Kitayama, 1991b) or book chapter (Markus \& Kitayama, 1991a) to justify the designation of those attributes as collectivistic (or interdependent). Unfortunately, neither the article nor the chapter validated empirically those attributes, and oddly enough, the article (Markus \& Kitayama, 1991b, p. 230) offered "hardworking" (p. 230) as an example of an attribute that is potentially important to persons with an independent self-construal. Thus, the studies that failed to carry out dimension validation included as part of the collectivistic dimension a conglomerate of attributes relevant not only to collectivism but also to individualism. Hence, this practice accounts for the ambiguous findings.

In contrast, when the 11 (5 Eastern, 6 Western) samples that validated the comparison dimension are considered, the results are clear. Both Westerners and Easterners self-enhance, but on different dimensions: Westerners self-enhance on attributes relevant to the individualistic dimension, Easterners on attributes relevant to the collectivistic dimension. This pattern is consistent with Sedikides et al.'s (2003) findings. The enigma, then, of these findings is solved. Sedikides et al. replicated the findings of those researchers who validated the comparison dimension, but did not 
replicate the findings of those researchers who failed to validate the comparison dimension. ${ }^{8}$

\section{Is the Better-Than-Average Effect a Valid Measure of Self-Enhancement?}

In our primary research (Sedikides et al., 2003), we indexed self-enhancement in terms of better-than-average judgments. We adopted this practice because the better-than-average effect (a) is regarded as a robust and valid signature of self-enhancement (Sedikides \& Gregg, 2003), (b) has been obtained in a great many studies, on numerous dimensions, and with an assortment of measurement techniques and populations (Alicke \& Govorun, in press), and (c) affords participants interpretational and judgmental latitude, thus giving their self-enhancement tendencies the opportunity to flourish.

Heine (2005) impugned the notion that the above-average effect is a valid measure of self-enhancement. "I suggest," he stated, "that the better-than-average effect. . reveals its unique pattern because it is not a pure measure of self-enhancement" (p. 534). He proceeded to list research reporting that people view any randomly selected person, or fragrance for that matter, as better than average (Giladi \& Klar, 2002; Klar \& Giladi, 1997, 1999). Heine concluded that the better-than-average effect "has nothing to do with self-enhancing motivations, but [with] the different ways that people process singular versus distributional information" (p. 534).

We dispute Heine's (2005) conclusion. In essence, Heine's hasty dismissal of the better-than-average effect has to do with the question of mechanisms (or nonmotivational explanations) underlying the effect. The four primary such mechanisms are selective recruitment, focalism, egocentrism, and individuated-entity versus aggregate comparison (Alicke \& Govorun, in press). Selective recruitment refers to the strategic choice of downward comparison targets or behavioral evidence that favors the self (Alicke, Vredenburg, Hiatt, \& Govorun, 2001). Focalism refers to the positioning of the self as the subject, and the average person as the target, of judgment (Eiser, Pahl, \& Prins, 2001). Somewhat relatedly, egocentrism refers to a focus on one's own positive characteristics and the accompanying heightened availability of one's own behaviors (Klar \& Giladi, 1999). Finally, individuated-entity versus aggregate comparison refers to a single entity (i.e., a person) being compared with an aggregate (i.e., the average peer; Klar, 2002). This last mechanism is the one to which Heine alluded in impugning the better-than-average effect and the one to which we now turn.

Klar and his colleagues (Giladi \& Klar, 2002; Klar, 2002; Klar \& Giladi, 1997) have shown that any member of a liked group (e.g., a randomly selected student at one's university, police officer, soap fragrance) is rated more positively than the group average (e.g., average student at one's university, average police officer, average fragrance) and that any member of a disliked group is evaluated more negatively than the group average. These findings raise the possibility that the better-than-average effect is due to the greater weight that perceivers place on any individuated entity versus an aggregate. This possibility, however, is ruled out by conceptually identical findings in which the better-than-average effect is diminished but not eliminated when the individuated entity is the self (Alicke, Klotz, Breitenbecher, Yurak, \& Vredenburg, 1995). That is, compared with other individuated entities, the self has a privileged position: The better-than-average effect is greater when the self is the individuated entity. Thus, the research by Klar and his colleagues cannot fully account for the better-thanaverage effect, as their research is in no position to explain the augmented favorability accorded to the self in comparison to any other individuated entity.

Instead, the individuated entity versus aggregate mechanism as well as selective recruitment, focalism, and egocentrism are best thought of as moderators of the better-than-average effect (Alicke $\&$ Govorun, in press). These moderators cannot supplant motivational interpretations for the effect. The moderators are not alternatives to motivational explanations. As Alicke and Govorun (in press) pointed out, motivational accounts explain why the effect occurs, whereas the earlier mentioned moderators or mechanisms explain how it occurs. To make a convincing argument that these moderators, either in isolation or combination, can supplant motivational interpretations, it would be necessary to show that they eliminate the effect. They do not. They attenuate the effect, but they do not eliminate it. Although various nonmotivational moderators contribute to the better-than-average effect (Chambers \& Windschitl, 2004), the effect is largely due to the desire to maintain a self-view that compares favorably with one's peers.

There is excellent evidence for the proposition in favor of motivational underpinnings of the better-than-average effect. We briefly review four sources of evidence. First, the effect is a function of attributes that are more strongly tethered to the self, such as positive or controllable traits. When comparing themselves with the average college student, participants rate themselves more favorably on positive traits, but less favorably on negative traits (Alicke, 1985). Similarly, they rate themselves more favorably on positive controllable traits, but less favorably on negative controllable traits (Alicke, 1985). Second, the effect emerges more strongly when there is interpretational latitude, such as when participants rate themselves on moral rather than intellectual behaviors, presumably because the former is more subjective (and thus unverifiable) than the latter (Allison, Messick, \& Goethals, 1989; Van Lange \& Sedikides, 1998). Third, the effect emerges even under cognitive load conditions (Alicke et al., 1995, Study 7), thus supporting the notion that it is an instance of automatic self-enhancement (Paulhus, 1993). Finally, and most important, the effect emerged selectively both in our primary research (Sedikides et al., 2003) and in the meta-analysis. For Westerners, it emerged when they compared themselves with the average peer on individualistic attributes (which were personally important) but not on collectivistic ones; for Easterners, it emerged when they compared themselves with the average peer on collectivistic at-

\footnotetext{
${ }^{8}$ We hope that our treatment of the dimension validation issue addresses another concern that Heine (2005) expressed, namely the exact meaning of the individualistic and collectivistic attributes on which participants made better-than-average judgments (Sedikides et al., 2003). Heine questioned the extent to which some of these attributes are positive or negative. To him, four behaviors and four traits appear negative rather than positive. Our response is that positivity or negativity, as judged by the researcher, is rather irrelevant. What is relevant, instead, is whether participants themselves perceived the attributes as individualistic or collectivistic, which was obviously the case (Sedikides et al., 2003, Pilot Study). A more direct response, though, to Heine's concern is that our results generalized across behaviors or traits that he regarded as negative.
} 
tributes (which were personally important) but not on individualistic ones. Heine (2005) would be hard pressed to explain why the effect comes and goes as a function of the motivational significance of the judgment. How could Klar and colleagues' (Giladi \& Klar, 2002; Klar, 2002; Klar \& Giladi, 1997) interesting research explain this pattern? Why is Heine's evocation of a main effect interpretational framework adequate to account for our interaction pattern? We conclude that the better-than-average effect is a valid signature of self-enhancement phenomena (i.e., of motivated social cognition).

\section{Is Evidence for Pancultural Self-Enhancement Limited to the Present Investigation?}

Evidence for pancultural self-enhanzcement is not limited to the reported meta-analyses. Indeed, the current results are consistent with findings from several emerging literatures. In particular, mounting recognition of the tactical nature of selfenhancement, implicit measures of self-regard, and crosscultural predictors of psychological health all point to the universality of self-enhancement.

\section{Mounting Recognition of the Tactical Nature of Self-Enhancement}

Although, on average (i.e., ignoring the dimension of comparison), Easterners may self-enhance less than Westerners (Heine \& Hamamura, 2004; Mezulis, Abramson, Hyde, \& Hankin, 2004), the tactical nature of self-enhancement has begun to be more fully appreciated (Kurman, 2001). In a recent special issue of the Journal of Cross-Cultural Psychology, all articles obtained support for the notion that Easterners self-enhance tactically (Brown, 2003). In particular, Eastern self-enhancement emerged when selfpresentational (Kobayashi \& Greenwald, 2003; Kudo \& Numazaki, 2003; Kurman, 2003) or modesty (Muramoto, 2003) concerns were minimized and the interaction context was competitive rather than cooperative (Takata, 2003). In fact, not only do Japanese rate themselves more positively than their peers or members of the general population, but they also rate themselves more positively than a member of their family (Brown \& Kobayashi, 2002).

\section{Implicit Self-Regard}

Implicit measures of self-regard indicate that Easterners and Westerners think positively of themselves. Response time latencies to pairings of self versus other with positive versus negative adjectives reveal that Japanese and Americans regard self more positively and less negatively than they regard other (Kitayama \& Uchida, 2003; Kobayashi \& Greenwald, 2003). Conceptually similar patterns of self-enhancement have been obtained among Easterners with other implicit measures. Name-letter preferences, for example, evidence self-enhancement in Japan (Kitayama \& Karasawa, 1997; Murakami \& Yamaguchi, 2000), Singapore (Pelham et al., 2005), Thailand (Hoorens, Nuttin, Erdelyi-Herman, \& Pavakanun, 1990), and southern European countries (Nuttin, 1987). Birthday-number preferences (Kitayama \& Karasawa, 1997) and semantic priming paradigms (Hetts, Sakuma, \& Pelham, 1999) also reveal an implicitly favored self among Easterners.

\section{Psychological Health}

Self-enhancement (as indexed by the better-than-average effect) is associated with psychological health in Western culture (Taylor et al., 2003b), and the same pattern is obtained in Eastern culture. Here, not only self-enhancing social comparisons, but also selfserving attributions, perceptions of self-efficacy, and optimism are negatively associated with depression and positively associated with self-esteem and life satisfaction among Japanese (Kobayashi \& Brown, 2003; Kurman, 2003), Chinese (Anderson, 1999), Hong Kongers (Stewart et al., 2003), Bosnians (Bonanno et al., 2002), Koreans (Chang, Sanna, \& Yang, 2003), Singaporeans (Kurman \& Siram, 1997), and Singaporean Chinese (Kurman, 2003).

\section{Coda}

We responded to Heine's (2005) attentive challenge by establishing the cultural universality of self-enhancement motivation. Members of both Eastern and Western culture self-enhance tactically. Easterners self-enhance on attributes relevant to their cultural ideal of collectivism (in part, because this ideal is personally valued), whereas Westerners self-enhance on attributes relevant to the cultural ideal of individualism (in part, because this ideal is personally valued). The same basic motivation is manifested differently in different cultures. East meets West with tactical selfenhancement. To paraphrase Rudyard Kipling's (1889) The Ballad of East and West,

Oh, East Is East, and West Is West, and Never the Twain Shall Meet, Except that both do self-enhance, albeit in ways discrete!

\section{References}

Alicke, M. D. (1985). Global self-evaluation as determined by the desirability and controllability of trait adjectives. Journal of Personality and Social Psychology, 49, 1621-1630.

Alicke, M. D., \& Govorun, O. (in press). The better-than-average effect. In M. D. Alicke, D. A. Dunning, \& J. I. Krueger (Eds.), The self in social judgment. Philadelphia: Psychology Press.

Alicke, M. D., Klotz, M. L., Breitenbecher, D. L., Yurak, T. J., \& Vredenburg, D. S. (1995). Personal contact, individuation, and the betterthan-average effect. Journal of Personality and Social Psychology, 68, $804-825$.

Alicke, M. D., Vredenburg, D. S., Hiatt, M., \& Govorun, O. (2001). The "better than myself" effect. Motivation and Emotion, 25, 7-22.

Allison, S. T., Messick, D. M., \& Goethals, G. R. (1989). On being better but not smarter than others: The Muhammad Ali effect. Social Cognition, 7, 275-296.

Anderson, C. A. (1999). Attributional style, depression, and loneliness: A cross-cultural comparison of American and Chinese students. Personality and Social Psychology Bulletin, 25, 482-499.

Bonanno, G. A., Field, N. P., Kovacevic, A., \& Kaltman, S. (2002). Self-enhancement as a buffer against extreme adversity: Civil war in Bosnia and traumatic loss in the United States. Personality and Social Psychology Bulletin, 28, 184-196.

Brown, J. D. (2003). The self-enhancement motive in collectivistic cultures: The rumors of my death have been greatly exaggerated. Journal of Cross-Cultural Psychology, 34, 603-605.

Brown, J. D., \& Kobayashi, C. (2002). Self-enhancement in Japan and America. Asian Journal of Social Psychology, 5, 145-167.

Chambers, J. R., Windschitl, P. D. (2004). Biases in social comparative judgments: The role of nonmotivated factors in above-average and comparative-optimism effects. Psychological Bulletin, 130, 813-838. 
Chang, E. C., Sanna, L. J., \& Yang, K. (2003). Optimism, pessimism, affectivity, and psychological adjustments in U.S. and Korea: A test of a mediation model. Personality and Individual Differences, 34, 11951208.

Eiser, J. R., Pahl, S., \& Prins, Y. R. A. (2001). Optimism, pessimism, and the direction of self-other comparisons. Journal of Experimental Social Psychology, 37, 77-84.

Field, A. P. (2001). Meta-analysis of correlation coefficients: A Monte Carlo comparison of fixed- and random-effects methods. Psychological Methods, 6, 161-180.

Field, A. P. (2003). The problems using fixed-effects models of metaanalysis on real-world data. Understanding Statistics, 2, 77-96.

Fukunishi, I., Nakagawa, T., Nakamura, H., Li, K., Hua, Z. Q., \& Kratz, T. S. (1996). Relationships between Type A behavior, narcissism, and maternal closeness for college students in Japan, the United States of America, and the People's Republic of China. Psychological Reports, 78, 939-944.

Giladi, E. E., \& Klar, Y. (2002). When standards are wide of the mark: Nonselective superiority and bias in comparative judgments of objects and concepts. Journal of Experimental Psychology: General, 131, 538551 .

Hedges, L. V., \& Vevea, J. L. (1998). Fixed- and random-effects models in meta-analysis. Psychological Methods, 3, 486-504.

Heine, S. J. (2005). Where is the evidence for pancultural self-enhancement?: A reply to Sedikides, Gaertner, and Toguchi (2003). Journal of Personality and Social Psychology, 89, 531-538.

Heine, S. J., \& Hamamura, T. (2004). In search of East Asian selfenhancement. Unpublished manuscript, University of British Columbia.

Heine, S. J., Kitayama, S., \& Lehman, D. R. (2001). Cultural differences in self-evaluation: Japanese readily accept negative self-relevant information. Journal of Cross-Cultural Psychology, 32, 434-443.

Heine, S. J., Kitayama, S., Lehman, D. R., Takata, T., Ide, E., Leung, C., \& Matsumoto, H. (2001). Divergent consequences of success and failure in Japan and North America: An investigation of self-improving motivations and malleable selves. Journal of Personality and Social Psychology, 81, 599-615.

Heine, S. J., \& Lehman, D. R. (1995). Cultural variation in unrealistic optimism: Does the West feel more vulnerable than the East? Journal of Personality and Social Psychology, 72, 1268-1283.

Heine, S. J., \& Lehman, D. R. (1997). Culture, dissonance, and selfaffirmation. Personality and Social Psychology Bulletin, 23, 389-400.

Heine, S. J., \& Lehman, D. R. (1999). Culture, self-discrepancies, and self-satisfaction. Personality and Social Psychology Bulletin, 25, 915925

Heine, S. J., \& Lehman, D. R. (2004). Move the body, change the self: Acculturative effects on the self-concept. In M. Schaller \& C. S. Crandall (Eds.), The psychological foundations of culture (pp. 305-331). Mahwah, NJ: Erlbaum.

Heine, S. J., Lehman, D. R., Markus, H. R., \& Kitayama, S. (1999). Is there a universal need for positive self-regard? Psychological Review, 106, 766-794.

Heine, S. J., \& Renshaw, K. (2002). Interjudge agreement, selfenhancement, and liking: Cross-cultural divergences. Personality and Social Psychology Bulletin, 28, 578-587.

Hetts, J. J., Sakuma, M., \& Pelham, B. W. (1999). Two roads to positive regard: Implicit and explicit self-evaluation and culture. Journal of Experimental Social Psychology, 35, 512-559.

Hoorens, V., Nuttin, J. M., Erdelyi-Herman, I., \& Pavakanun, U. (1990). Mastery pleasure versus mere ownership: A quasi-experimental crosscultural and cross-alphabetical test for the name letter effect. European Journal of Social Psychology, 20, 181-205.

Hornsey, M. J. \& Jetten, J. (2005). Loyalty without conformity: Tailoring self-perception as a means of balancing belonging and differentiation. Self and Identity, 4, 81-95.
Hunter, J. E., \& Schmidt, F. L. (2000). Fixed effects vs. random effects meta-analysis models: Implications for cumulative knowledge in psychology. International Journal of Selection and Assessment, 8, 275-292.

Ito, T. (1999). Self-enhancement tendency and other evaluations: An examination of the "better-than-average effect." Japanese Journal of Psychology, 70, 367-374.

Kipling, R. (1889). The ballad of East and West. In E. C. Stedman (Ed., 1895), A Victorian anthology, 1837-1895. Cambridge, England: Riverside Press.

Kitayama, S., \& Karasawa, M. (1997). Implicit self-esteem in Japan: Name letters and birthday numbers. Personality and Social Psychology Bulletin, 23, 736-742.

Kitayama, S., Markus, H. R., Matsumoto, H., \& Norasakkunkit, V. (1997). Individual and collective processes in the construction ot the self: Self-enhancement in the United States and self-criticism in Japan. Journal of Personality and Social Psychology, 72, 1245-1267.

Kitayama, S., \& Uchida, Y. (2003). Explicit self-criticism and implicit self-regard: Evaluating self and friend in two cultures. Journal of Experimental Social Psychology, 39, 476-482.

Klar, Y. (2002). Way beyond compare: Nonselective superiority and inferiority biases in judging randomly assigned group members relative to their peers. Journal of Experimental Social Psychology, 38, 331-351.

Klar, Y., \& Giladi, E. E. (1997). No one in my group can be below the group's average: A robust positivity bias in favor of anonymous peers. Journal of Personality and Social Psychology, 73, 885-901.

Klar, Y., \& Giladi, E. E. (1999). Are most people happier than their peers, or are they just happy? Personality and Social Psychology Bulletin, 25, $585-594$.

Kobayashi, C., \& Brown, J. D. (2003). Self-esteem and self-enhancement in Japan and America. Journal of Cross-Cultural Psychology, 34, 567580.

Kobayashi, C., \& Greenwald, A. G. (2003). Implicit-explicit differences in self-enhancement for Americans and Japanese. Journal of CrossCultural Psychology, 34, 522-541.

Kudo, E., \& Numazaki, M. (2003). Explicit and direct self-serving bias in Japan: Reexamination of self-serving bias for success and failure. Journal of Cross-Cultural Psychology, 34, 511-521.

Kurman, J. (2001). Self-enhancement: Is it restricted to individualistic cultures? Personality and Social Psychology Bulletin, 12, 1705-1716.

Kurman, J. (2003). Why is self-enhancement low in certain collectivistic cultures?: An investigation of two competing explanations. Journal of Cross-Cultural Psychology, 34, 496-510.

Kurman, J., \& Siram, N. (1997). Self-enhancement, generality of selfevaluation, and affectivity in Israel and Singapore. Journal of CrossCultural Psychology, 28, 421-441.

Markus, H. R., \& Kitayama, S. (1991a). Cultural variation in the selfconcept. In G. R. Goethals \& J. Strauss (Eds.), Multidisciplinary perspectives on the self (pp. 18-48). New York: Springer-Verlag.

Markus, H. R., \& Kitayama, S. (1991b). Culture and the self: Implications for cognition, emotion, and motivation. Psychological Review, 98, 224 253.

Mezulis, A. H., Abramson, L. Y., Hyde, J. S., \& Hankin, B. L. (2004). Is there a universal positive bias in attributions?: A meta-analytic review of individual, developmental, and cultural differences in the self-serving attributional bias. Psychological Bulletin, 130, 711-747.

Murakami, F., \& Yamaguchi, S. (2000). Implicit self-concept among Japanese. Paper presented at the 15th congress of International Association for Cross-Cultural Psychology, Pultusk, Poland.

Muramoto, Y. (2003). An indirect self-enhancement in relationship among Japanese. Journal of Cross-Cultural Psychology, 34, 552-566.

National Research Council. (1992). Combining information: Statistical issues and opportunities for research. Washington, DC: National Academy Press. 
Norasakkunkit, V., \& Kalick, S. M. (2002). Culture, ethnicity, and emotional distress measures: The role of self-construal and selfenhancement. Journal of Cross-Cultural Psychology, 33, 56-70.

Nuttin, J. M., Jr. (1987). Affective consequences of mere ownership: The name letter effect in twelve European languages. European Journal of Social Psychology, 17, 381-402.

Paulhus, D. L. (1993). Bypassing the will: The automatization of affirmations. In D. M. Wegner \& J. M. Pennebaker (Eds.), Handbook of mental control (pp. 573-587). Englewood Cliffs, NJ: Prentice Hall.

Pelham, B. W., Koole, S. L., Hardin, C. D., Hetts, J. J., Seah, E., \& DeHart, T. (2005). Gender moderates the relation between implicit and explicit self-esteem. Journal of Experimental Social Psychology, 41, 84-89.

Pyszczynski, T., Greenberg, J., Solomon, S., Arndt, J., \& Schimel, J. (2004a). Converging toward an integrated theory of self-esteem: Reply to Crocker and Nuer (2004), Ryan and Deci (2004), and Leary (2004). Psychological Bulletin, 130, 483-488.

Pyszczynski, T., Greenberg, J., Solomon, S., Arndt, J., \& Schimel, J. (2004b). Why do people need self-esteem?: A theoretical and empirical review. Psychological Bulletin, 130, 435-468.

Sedikides, C. (1993). Assessment, enhancement, and verification determinants of the self-evaluation process. Journal of Personality and Social Psychology, 65, 317-338.

Sedikides, C., Campbell, W. K., Reeder, G., \& Elliot, A. J. (1998). The self-serving bias in relational context. Journal of Personality and Social Psychology, 74, 378-386.

Sedikides, C., Campbell, W. K., Reeder, G., \& Elliot, A. J. (2002). The self in relationships: Whether, how, and when close others put the self "in its place." European Review of Social Psychology, 12, 237-265.

Sedikides, C., Gaertner, L., \& Toguchi, Y. (2003). Pancultural selfenhancement. Journal of Personality and Social Psychology, 84, 60-79.

Sedikides, C., \& Green, J. D. (2000). On the self-protective nature of inconsistency/negativity management: Using the person memory paradigm to examine self-referent memory. Journal of Personality and Social Psychology, 79, 906-922.

Sedikides, C., \& Gregg, A. P. (2003). Portraits of the self. In M. A. Hogg \& J. Cooper (Eds.), Sage handbook of social psychology (pp. 110-138). London: Sage.

Sedikides, C., Herbst, K. C., Hardin, D. P., \& Dardis, G. J. (2002).
Accountability as a deterrent to self-enhancement: The search for mechanisms. Journal of Personality and Social Psychology, 83, 592-605.

Sedikides, C., \& Strube, M. J. (1997). Self-evaluation: To thine own self be good, to thine own self be sure, to thine own self be true, and to thine own self be better. In M. P. Zanna (Ed.), Advances in experimental social psychology (Vol. 29, pp. 209-269). New York: Academic Press.

Singelis, T. M. (1994). The measurement of independent and interdependent self-construals. Personality and Social Psychology Bulletin, 20, $580-591$.

Stewart, S. M., Byrne, B. M., Lee, P. W. H., Ho, L. M., Kennard, B. D., Hughes, C., \& Emslie, G. (2003). Personal versus interpersonal contributions to depressive symptoms among Hong Kong adolescents. International Journal of Psychology, 38, 160-169.

Takata, T. (2003). Self-enhancement and self-criticism in Japanese culture: An experimental analysis. Journal of Cross-Cultural Psychology, 34, $542-551$.

Taylor, S. E., Lerner, J. S., Sherman, D. K., Sage, R. M., \& McDowell, N. K. (2003a). Are self-enhancing cognitions associated with healthy or unhealthy biological profiles? Journal of Personality and Social Psychology, 85, 605-615.

Taylor, S. E., Lerner, J. S., Sherman, D. K., Sage, R. M., \& McDowell, N. K. (2003b). Portrait of the self-enhancer: Well-adjusted and wellliked or maladjusted and friendless? Journal of Personality and Social Psychology, 84, 165-176.

Van Lange, P. A. M., \& Sedikides, C. (1998). Being more honest but not necessarily more intelligent than others: Generality and explanations for the Muhammad Ali effect. European Journal of Social Psychology, 28, $675-680$.

Vevea, J. L., \& Hedges, L. V. (1995). A general linear model for estimating effect size in the presence of publication bias. Psychometrika, 60, $419-435$.

Vevea, J. L., \& Woods, C. M. (2004). Publication bias in research synthesis: Sensitivity analysis using a priori weight functions. Manuscript submitted for publication.

Received May 13, 2004

Revision received October 21, 2004

Accepted November 4, 2004

\section{Instructions to Authors}

For Instructions to Authors, please visit www.apa.org/journals/psp and click on the "Instructions to Authors" link in the Journal Info box on the right. 